\title{
II4. THE IRON OF THE PLASMA
}

\author{
BY SIDNEY LIONEL TOMPSETT \\ - From the Biochemical Laboratory of the Institute of Pathology, \\ the Royal Infirmary, Glasgow
}

(Received 10 April 1940)

THE iron content of the plasma is small but it is probably of great importance as transport iron. In the normal subject the range is narrow and results obtained by various workers within recent years have shown general agreement, the figures ranging from about 0.1 to $0.2 \mathrm{mg}$. Fe per $100 \mathrm{ml}$. [Barkan, 1927; Fowweather, 1934; Tompsett, 1934; Moore, 1937].

Barkan [1925] found that plasma Fe was not ultrafiltrable but became so after incubation of the plasma with dilute $\mathrm{HCl}$ at $37^{\circ}$. Tompsett [1934] found that only a small fraction of the plasma $\mathrm{Fe}$ could be recovered in trichloroacetic acid extracts and that added $\mathrm{Fe}$ (as iron alum) could not be recovered quantitatively in such extracts. Fowweather [1934] made a similar observation. The writer has found that plasma $\mathrm{Fe}$ and added Fe could be recovered quantitatively in trichloroacetic acid extracts if thiolacetic acid, a reducing agent, had previously been added. It has also been found that whereas ferrous Fe could be recovered quantitatively in trichloroacetic acid extracts of materials containing phosphatides or phosphoproteins, ferric Fe could not. Plasma Fe was shown to be in the ferric state in vitro. In later work, Barkan [1937] noted that the plasma Fe could be recovered quantitatively in trichloroacetic acid extracts provided that the plasma had previously been incubated with dilute $\mathrm{HCl}$ at $37^{\circ}$ for $24 \mathrm{hr}$.

The following experiments were carried out in order to obtain a clearer insight into the nature of the plasma $\mathrm{Fe}$ and the Barkan phenomenon.

In the first experiments, the influence of plasma on the dialysis of ferrous and ferric salts was studied. To $5 \mathrm{ml}$. of plasma was added $1 \mathrm{mg}$. Fe (ferrous sulphate, iron alum, iron ammonium citrate) and the mixtures were dialysed against $15 \mathrm{ml}$. water for $4 \mathrm{hr}$. At the end of this period the $\mathrm{Fe}$ contents of the dialysates were estimated with thiolacetic acid and $\mathrm{NH}_{3}$ [Tompsett, 1934]. Typical results are shown in Table 1 , where it will be seen that whereas ferrous Fe dialysed easily, ferric Fe dialysed hardly at all.

\section{Table 1. Typical results obtained in a study of the dialysis of added Fe from plasma}

$1 \mathrm{mg}$. Fe added; the figures represent $\mathrm{mg}$. Fe that have dialysed in $4 \mathrm{hr}$.

$\begin{array}{ll}\text { Ferrous sulphate } & 0 \cdot 30 \\ \text { Iron alum } & 0 \cdot 01 \\ \text { Iron ammonium citrate } & 0 \cdot 01 \\ \text { Iron alum (plasma } & 0 \cdot 18 \\ \text { containing } 0 \cdot 8 \% \mathrm{HCl} \text { ) } & \end{array}$

Tompsett [1940] has shown that certain foodstuffs are capable of reducing ferric Fe to the ferrous state, particularly at acid reactions. It was suggested that proteins were chiefly responsible for this phenomenon. It seemed possible that serum and plasma could have this property. $1 \mathrm{mg}$. Fe (as iron alum) was added to $5 \mathrm{ml}$. plasma. On standing no appreciable reduction occurred. On standing at acid reactions reduction did occur, as evidenced by the fact that 
after standing $1 \mathrm{hr}$. in the presence of $0.8 \% \mathrm{HCl}$, a red colour developed on the addition of $\alpha \alpha^{\prime}$-dipyridyl.

The dialysis of ferric Fe from acidified plasma $(0.8 \% \mathrm{HCl})$ was then examined. As will be seen from the results shown in Table 1 ferric $\mathrm{Fe}$ appeared to dialyse readily under these conditions. Upon examination with $\alpha \alpha^{\prime}$-dipyridyl, it was found that the whole of the $\mathrm{Fe}$ in the dialysates was in the ferrous state.

The question naturally arises as to the nature of the substances producing this reduction. It might be due to ascorbic acid; the writer, however, is rather of the opinion that the plasma proteins are responsible. Ascorbic acid has been found to reduce ferric $\mathrm{Fe}$ as readily in neutral as in acid solution, whereas in the case of plasma an acid reaction appears to be necessary or to be very definitely favourable. This problem requires further investigation.

\section{Discussion}

The Fe present in samples of plasma obtained under conditions which do not prevent the re-oxygenation of haemoglobin is in the ferric state. This accounts for the fact that the plasma Fe, unless subjected to special treatment, is not ultrafiltrable. The phosphatides are probably more concerned with this phenomenon than the proteins.

It is now possible to explain the "Barkan phenomenon". It has been shown that the plasma $\mathrm{Fe}$ becomes reduced to the ferrous state when the plasma is acidified and allowed to stand. Ferrous $\mathrm{Fe}$ is ultrafiltrable.

Barkan has referred to the plasma $\mathrm{Fe}$ as the "easily split iron". This term would suggest that such $\mathrm{Fe}$ is present as a compound distinct from complexes of $\mathrm{Fe}$ which are generally recognized. The $\mathrm{Fe}$ of the plasma is probably present as a salt, although undissociated, with such substances as phosphatides, proteins etc. There is no reason to suggest that it is combined with any particular substance or group of substances and it is quite likely distributed amongst a number of them. In view of the facts discussed above, the writer is of the opinion that the term plasma $\mathrm{Fe}$ is a sufficient description.

The Fe of the plasma has been found to be wholly in the ferric state and as such undissociated. This does not indicate that this is the permanent state of the plasma $\mathrm{Fe}$ in vivo. It seems very probable that at some stage the plasma $\mathrm{Fe}$ will, at least in part, be changed into the ferrous state, i.e. become capable of dissociation and ultrafiltrable. That this must occur seems obvious, for otherwise it seems difficult to visualize how the plasma $\mathrm{Fe}$, if it is to be regarded as transport $\mathrm{Fe}$, is to become utilizable.

\section{SUMMARY}

The "Barkan effect" observed in plasma and serum has been shown to be due to the reduction of the plasma $\mathrm{Fe}$ to the ferrous state with a consequent change from a non-ultrafiltrable to an ultrafiltrable condition.

I wish to thank Dr A. B. Anderson for his helpful criticism and advice.

\section{REFERENCES}

Barkan (1925). Hoppe-Seyl. Z. 148, 124.

- (1927). Hoppe-Seyl. Z. 171, 194.

- (1937). Klin. Wschr. 16, 300.

Fowweather (1934). Biochem. J. 28, 1160.

Moore (1937). J. clin. Invest. 16, 613.

Tompsett (1934). Biochem. J. 28, 1536, 1802.

(1940). Biochem. J. 34, 961 . 